
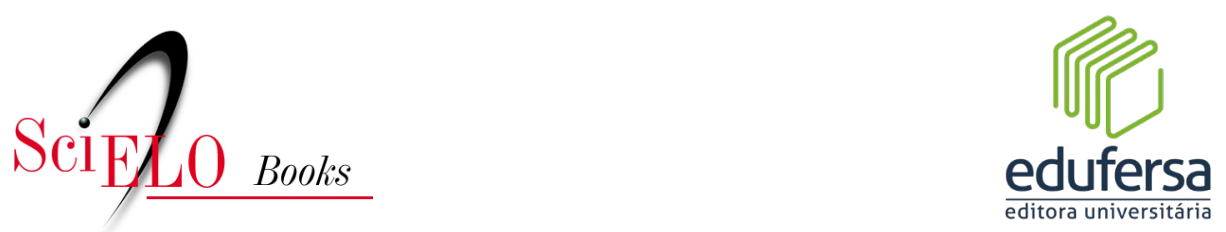

\title{
Parte II - História e Sociedade 5 - O futuro do passado: imprensa e comemorações na fabricação da memória sobre a libertação dos escravos em Mossoró (1883-1931)
}

Marcílio Lima Falcão

\section{SciELO Books / SciELO Livros / SciELO Libros}

FALCÃO, M. L. O futuro do passado: imprensa e comemorações na fabricação da memória sobre a libertação dos escravos em Mossoró (1883-1931). In: OLIVEIRA, A. M., SILVA, L. R., and FALCÃO, M. L., eds. Sociedade e cultura no Rio Grande do Norte: diálogos interdisciplinares [online]. Mossoró: EdUFERSA, 2021 , pp. 97-115. ISBN: 978-65-87108-24-7.

https://doi.org/10.7476/9786587108582.0006.

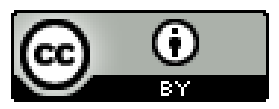

All the contents of this work, except where otherwise noted, is licensed under a Creative Commons Attribution 4.0 International license.

Todo o conteúdo deste trabalho, exceto quando houver ressalva, é publicado sob a licença Creative Commons Atribição 4.0.

Todo el contenido de esta obra, excepto donde se indique lo contrario, está bajo 


\title{
5 O FUTURO DO PASSADO: IMPRENSA E COMEMORAÇÕES NA FABRICAÇÃO DA MEMÓRIA SOBRE A LIBERTAÇÃO DOS ESCRAVOS EM MOSSORÓ (1883-1931)
}

\author{
Marcílio Lima Falcão
}

Em 1902, quando João da Escóssia ${ }^{46}$ fez circular, pela segunda vez, o jornal O Mossoroense ${ }^{47}$, e uma de suas primeiras ações foi republicar

46 João da Escóssia nasceu em 27 de maio de 1873 e faleceu em 14 de janeiro de 1919. Filho de Jeremias da Rocha Nogueira, João da Escóssia implementou algumas mudanças, como o uso de ilustrações a partir de xilogravuras (ESCÓSSIA ROSADO, 1992, p. 18).

47 Fundado em 17 de outubro de 1872, o Jornal O Mossoroense era representante do Partido Liberal, em Mossoró, defendia os interesses da maçonaria e sofria forte oposição do Partido Conservador local, dirigido pelo padre Antônio Joaquim Rodrigues. Essas rivalidades políticas se estenderam aos posicionamentos doutrinários e religiosos envolvendo o jornalista e a Igreja Católica. Para Jaime Hipólito Dantas, O Mossoroense passou por três momentos de funcionamento. A primeira fase (1872 a 1875) marca os conflitos com a Igreja Católica. Na segunda fase (1902 a 1935), foi dirigido por João da Escóssia (filho de Jeremias), que transformou a produção e circulação do jornal, ao utilizar xilogravuras e fazê-lo circular por três vezes na semana (antes circulava quinzenalmente). Além disso, transformou o jornal no órgão do Partido Republicano Federal. Na terceira fase, sob o comando de Lauro da Escóssia, começou a circular em 1946 e foi fechado em 1964, por 
as matérias de o Libertador, um outro jornal, de origem cearense, que tratara sobre a libertação dos escravos em Mossoró, a 30 de setembro de $1883 .{ }^{48} \mathrm{O}$ interesse foi a inserção da trajetória familiar dos Escóssias ${ }^{49}$, no imaginário político local, a partir de duas estratégias: a fabricação de uma memória assentada em um passado considerado republicano e abolicionista; e a construção de um calendário cívico municipal que aureolasse o 30 de setembro como a mais importante data comemorativa.

Entre os meios para a efetivação dessas estratégias estavam o cuidado de selecionar o que deveria ser escrito e comemorado, bem como a transformação de O Mossoroense em "guardião" do passado da cidade. Desse modo, por toda a primeira metade do século XX, o jornal foi o principal narrador e incentivador das comemorações dos feitos

conta da instalação do governo militar. Ao retomar suas atividades nos anos de 1970, O Mossoroense passou a ser dirigido por Lauro da Escóssia. Em 1977, Lauro vendeu o jornal à Família Rosado (DANTAS, 2002, p. 33-34).

48 O Libertador era o órgão da Sociedade Libertadora Cearense. Em seu primeiro número (01 de janeiro de 1881) fez uma análise da situação brasileira em meio à escravidão, apontando o número de escravos ainda existente no país e os pequenos avanços que a questão havia tido nos espaços de discussão. Aponta a lei, de 28 de setembro de 1871, como algo importante, mas que não conseguiu alavancar um processo mais consistente para a questão servil. Ademais, defendeu que "sua missão é de amor, mas não vem trazer a paz [...] a liberdade só combate com a espada, porque a tyrannia não cede à razão e nem conhece o direito". O lema em seu estandarte é tomado de empréstimo da Revolução Francesa e, em francês, concluiu o editorial: allons, enfants de la patrie! Le jour de la gloire est arrivè! (LIBERTADOR, Fortaleza, p. 1, 1 jan. 1881.

49 A origem da Família Escóssia foi permeada pelos atritos envolvendo a Igreja Católica e a Maçonaria. Em 1873, Jeremias da Rocha Nogueira (liberal e maçom) teve o batismo de seu filho negado pelo vigário Antônio Joaquim (representante do Partido Conservador), por serem os pais e padrinhos membros da maçonaria. Tal situação levou Jeremias Nogueira a batizar o filho na Loja 24 de Junho, com o nome de João da Escóssia Nogueira. Casado com Noemi Dulcila de Souza, João da Escóssia teve 12 filhos, entre eles Lauro da Escóssia, que dirigiu o jornal O Mossoroense de 1946 a 1977 (ESCÓSSIA ROSADO, 1998, p. 21-22). 
gloriosos dos mossoroenses, dando lugar, em suas páginas, a novos acontecimentos, selecionados a partir da relevância político-social, nos cenários regional ou nacional e de acordo com a possibilidade de inclusão da participação de membros da Família Escóssia na narrativa jornalística.

Assim, a partir da circulação dos documentos sobre a abolição da escravidão e do mapeamento das transformações (apropriações e deslocamentos), ao longo do século XX, este artigo tem como finalidade analisar o papel da imprensa e das comemorações na fabricação da memória sobre a libertação dos escravos em Mossoró no período de 1883 a 1931.

\subsection{O Guardião do passado}

Por meio da leitura das folhas impressas número oitocentos, é possível afirmar que a reprovação à monarquia, em Mossoró, foi anterior à rejeição da escravidão. Em 1873, por exemplo, o jornal O Mossoroense utilizou o discurso da "Fala do Trono" para adjetivar o governo imperial como "imoral, corrompido" e responsável pelos "sofrimentos e dores da pátria" (O MOSSOROENSE, p. 1, 11 jan. 1873). Entre as críticas ao Império e a defesa da República, deu prioridade às matérias favoráveis aos liberais, tomando como adversário político local o Pe. Antônio Joaquim Rodrigues, líder do Partido Conservador, crítico ferrenho da maçonaria e representante local na Assembleia Provincial (ROSADO, 1992, p. 13).

Comandado por Jeremias da Rocha Nogueira, esse jornal apresentou-se como semanário político, comercial, noticioso e antijesuítico. Sua primeira fase, de 1872 a 1875, foi marcada pelas disputas políticas locais entre conservadores e liberais, o que contribuiu para a radicalização dos atritos entre os representantes da Igreja Católica (Pe. Antônio Joaquim) e a Maçonaria. Foi em O Mossoroense, portanto, que essa disputa teve sua maior expressão na imprensa local.

Ao retornar, em dezembro de 1902, o jornal se empenhou não somente em atacar a República, mas também em publicar documentos 
sobre a libertação local dos escravos a partir do que foi impresso, no calor da hora, pelo periódico cearense Libertador. Essa atitude pode ser entendida como um meio de João da Escóssia requerer, para sua família, uma memória que lhes colocaria como vanguarda na luta pela República e trabalho livre no Rio Grande do Norte.

Por outro lado, esse esforço pode ser compreendido como uma nova forma de narrar o passado da cidade, selecionando, a partir dos objetivos políticos, fatos que moveriam a circulação do jornal em sua segunda fase (1902-1934). Nesse sentido, o uso das narrativas sobre o 30 de setembro de 1883 e sua aproximação da população, por meio de comemorações que sacralizaram civicamente o tempo e o espaço, são vistos como estratégias dos Escóssias para estabelecer a abolição local como marco da campanha abolicionista nacional.

No jornal O Mossoroense, a evocação desse momento como a principal referência sobre o passado da cidade ocorreu por meio da publicação de atas, telegramas, cartas, poesias, hinos, artigos e biografias dos abolicionistas. O conteúdo desses textos ia, desde a desaprovação à recém-criada República, até o exemplo que o passado da cidade propiciou a construção do imaginário sobre a abolição da escravidão.

Em parte, essas publicações se justificam pela relação que a família Escóssia mantinha com a Maçonaria - instituição que alavancou o processo abolicionista local. Entretanto, admite-se a hipótese de que essa tenha sido uma tentativa de estabelecer, no imaginário social, O Mossoroense como o guardião do passado da cidade, expresso em símbolos, ritos comemorativos, crenças, discursos e representações sobre a libertação dos escravos (PESAVENTO, 1995, p. 24). Por essa razão, os Escóssias teriam incentivado a construção do calendário cívico municipal e dado ênfase à valorização dos abolicionistas, o que resultou no esquecimento das formas de resistência dos negros à escravidão em Mossoró.

Esse processo de esquecimento foi imprescindível à produção de uma memória gloriosa do 30 de setembro de 1883. Foi um movimento de cima para baixo, com o completo controle político e midiático das Sociedades Libertadoras Cearense e Mossoroense e da Maçonaria. Assim, pois, a libertação dos escravos em Mossoró, como data 
comemorativa, encontrou, na imprensa, seu lugar de circulação, ${ }^{50}$ tendo como principal representante local O Mossoroense, que, no intuito de manter a circulação da documentação sobre o acontecimento e incentivar as atividades comemorativas anuais, retomou, em sua segunda fase, a narrativa sobre o assunto.

Amparada por comemorações e discursos cívicos, a memória a respeito da abolição em Mossoró, construída pelos Escóssias, no jornal, reafirma os abolicionistas como homens imbuídos de ideais civilizatórios. A boa imagem desses homens foi reforçada ainda pelo uso da memória histórica presente no jornal Libertador, que concedeu a eles o status de heróis da cidade.

Por trazer matérias detalhadas, o Libertador foi, de fato, significativo para o trabalho jornalístico dos Escóssias em prol da construção de um lugar para Mossoró na história nacional. Uma matéria que mostra sua influência é a que narra a ocasião da festa do 30 de setembro de 1883, publicada no mesmo dia da abolição mossoroense. De forma antecipada, o jornal cearense divulgou, em Fortaleza, todo o protocolo a ser seguido na manhã do evento, em Mossoró, antes mesmo que ocorresse a solenidade da entrega das cartas de alforria.

Narrada como a data áurea da municipalidade, o 30 de setembro representa o instrumento por meio do qual as elites locais, com destaque para os Escóssias, buscaram sua inserção no imaginário social e a conquista de um lugar no contexto político republicano do início do século XX. Nessa empreitada, contaram com o jornal, veículo de informação no qual divulgaram o avanço civilizatório como um dos elementos do seu discurso (O MOSSOROENSE, p. 3, 30 set. 1909).

Tal avanço, ao coadunar com o discurso do profícuo crescimento da cidade de Mossoró, serviu aos interesses das autoridades em usarem as festividades cívicas, tanto nacionais como municipais, como momento

50 O jornal Correio de Natal fez uma edição especial sobre a libertação dos escravos em Mossoró. Os textos exaltaram o feito mossoroense, a participação da Libertadora Cearense e a importância da abolição mossoroense para alavancar a campanha no Rio Grande do Norte (CORREIO DE NATAL, p. 01 - 0430 set. 1883). 
de exibição das "novidades do viver moderno, a exemplo do telégrafo, do jornal, da luz elétrica, do automóvel, que dará a Mossoró ares de modernidade" (FERNANDES, 2009, p. 26). Esses avanços foram acompanhados pelas transformações urbanas, entre elas: inaugurações de praças, jardins, pavimentação de ruas e outros equipamentos que refletiam as mudanças na vida social e política da cidade.

Com efeito, o simbolismo desses espaços de sociabilidade, juntamente com a ritualística e liturgia cívica das comemorações anuais do 30 de setembro, efetivaram a monumentalização dos documentos que referenciavam, a partir da abolição local, Mossoró como terra da liberdade. A monumentalização pode ser compreendida pela importância que seu uso passa a ter para as instituições promotoras das comemorações cívicas. No momento em que os documentos são utilizados, eles fazem parte das relações de força que compõe essas atividades comemorativas e possibilitam refletir sobre a memória coletiva a partir das relações de poder presentes em sua constituição (LE GOFF, 1996, p. 545). Ademais, mostram que a operacionalização do uso do passado pelos Escóssias ocorreu por meio da associação entre passado e presente, isto é, pelo regime de historicidade que via no passado os elementos de efetivação e crença no futuro promissor.

No jornal O Mossoroense, a cidade é revelada como centro irradiador de uma decisão estratégica à "transformação social” da nação. Além disso, produziu-se o discurso que pôs a liberdade como referência do passado de Mossoró. Percebe-se, então, que o dever de memória da família Escóssia obteve êxito porque atuou no espaço comemorativo, que funciona como "meio de combate contra a amnésia coletiva, ou melhor, como forma de luta pela produção (e reprodução) de uma nova memória, assim elevada a uma espécie de garantia da necessária articulação entre o passado, o presente e o futuro" (CATROGA, 2005, p. 109).

\subsection{A Memória gloriosa}

Agenciada por diferentes formas de narrar o acontecimento (atas, hinos, poesias, biografias etc.), a fabricação da memória que propôs 
Mossoró como pioneira do abolicionismo nacional encontrou na relação passado/presente o espaço para que a comemoração não fosse monoliticamente a cristalização do passado, mas "uma transformação do presente, de tal forma que, se o passado aí for reencontrado, ele não fique o mesmo, mas seja também ele retomado e transformado" (DIEHL, 2002, p. 101). Sua importância se evidencia pela possibilidade de novas abordagens na (re)construção e ressignificação do acontecimento pelo ato comemorativo, por isso, mais do que lembrar os fatos, o uso jornalístico do passado fez das comemorações espaço de questionamentos da situação social e política republicana (KARNAL; TATSCH, 2011, p. 08-27).

Bella e encantadora miragem - a República vinha para nós nimbada da luz mais explendente de felicidades incomparáveis, não assinalando unicamente, triunphal avanço para um estado de civilização mais recomendável, mas também uma phase garantidora de um bem-estar geral e ambicionado.

Anteviamos a extraordinária elevação dos créditos e dos brios nacionaes, das honras e dignidades dos beneméritos servidores da pátria rehabilitada, a absoluta verdade da justiça inviolável, a excepcional grandeza desse mysterioso pedaço do continente americano, que parecia, no delírio de muitos, surgido dos mares e aparelhado n'aquelle mesmo dia para a grande vida invejável que o esperava.

No entanto, não pode ser mais desalentador, mais terrível, o desmentido, irreverente que de tudo nos tem dado os homens e as cousas dominadoras em Nosso Paíz (O MOSSOROENSE, p. 1,15 nov. 1904).

A República não trouxe o que o jornal tanto pregou contra a monarquia - a liberdade e a melhoria das condições de vida das camadas mais humildes. O saldo desolador, apresentado em O Mossoroense, refletiu o posicionamento dos Escóssias diante do naufrágio do sonho que a proclamação da República havia criado no tocante às "expectativas de renovação política de maior participação no poder por parte não 
só de contra-elites, mas também de camadas antes excluídas do jogo político" (CARVALHO, 1987, p. 22).

A desilusão apresentada diante do novo modelo político favoreceu a investida de $O$ Mossoroense na tentativa de inserir a cidade na escrita da história da nação por meio de seu passado glorioso. Desse modo, dados biográficos, textos e poesias de abolicionistas nacionais e locais, como José do Patrocínio, Paulo de Albuquerque, Damião de Souza Mello e Almino Affonso, apareceram com frequência nas páginas do jornal, especialmente nos anos iniciais da segunda fase de circulação (O MOSSOROENSE, p. 1, 16 fev. 1905).

O uso desses textos, ao fundamentar-se na memória comemorada sobre o 30 de setembro, contribuiu no sentido de evitar indagações sobre o processo de transição da escravidão ao trabalho livre em Mossoró, o que reforçava a oficialidade da narrativa jornalística de $O$ Mossoroense. Entretanto, a campanha abolicionista esteve no mesmo diapasão com que os Escóssias insistiram em reprovar as práticas que marcaram a cultura política da Primeira República. Em outras palavras, a exaltação aos abolicionistas e ao 30 de setembro omitiu as condições sociais dos homens e mulheres cujo passado escravo continuou como mácula à condição marginal diante dos direitos sociais essenciais à efetivação da cidadania.

Essa situação confirmou, em nível local, que a incorporação dos ex-escravos da sociedade mossoroense no pós-abolição ficou restrita ao mínimo que seu status de livres podia lhes oferecer em um contexto marcado pela preservação do caráter desigual e hierarquizado da sociedade brasileira (MACHADO, 2006, p. 149).

Desse modo, até o final de sua segunda fase, os Escóssias intercalaram a publicação de documentos com a programação das comemorações da abolição. Na edição $n^{\circ} 55$, por exemplo, o jornal comentou as comemorações do 30 de setembro e apontou a inauguração da Estátua da Liberdade, na Praça da Redenção, como:

[...] um marco commemorativo que attesta que na memória de um povo não se extingue a lembrança dos feitos gloriosos dos seus antepassados, e, como uma eloquente ironia, servirá elle 
de motivo para apostrofarmos os tyrannos, sempre que para aquella effigie tivermos de lançar as nossas vistas, lembrando-nos da clamorosa injustiça de um governo, que entrega seu povo ao extermínio pela negra fome (O MOSSOROENSE, p. 2, 30 set. 1904).

Como referência ao 30 de setembro, a Estátua da Liberdade era o ponto de convergência na relação que $O$ Mossoroense mantinha com a sociedade. Para além do jornal, outras instituições foram agregadas às solenidades da abolição da escravidão. Em 1909, o Grupo Escolar 30 de Setembro ficou a cargo das comemorações até a década de $1930 .{ }^{51}$ As atividades desempenhadas pela escola começavam pela manhã, com um desfile até a Praça da Redenção, onde cantavam o Hino da Libertadora Mossoroense e declamavam poesias. Em seguida, saiam em desfile rumo às casas dos abolicionistas e das sedes dos jornais $O$ Mossoroense e Comércio de Mossoró (O MOSSOROENSE, p. 1, 1910).

Durante anos, a comemoração do 30 de setembro ficou restrita às visitas à Estátua da Liberdade, às residências dos abolicionistas, inaugurações, realização do baile dos negros e às reuniões na Loja Maçônica 24 de Junho (O MOSSOROENSE, p. 1, 1910). A força da data comemorativa, no início do século XX, partiu dos interesses da Família Escóssia em associar sua trajetória política à campanha abolicionista, buscando, assim, a inserção no imaginário social, através da construção da dimensão nacional ao pioneirismo mossoroense. Sua importância foi tão grande que a relação era maior com a Lei do Ventre Livre ${ }^{52}$ que com a Lei Áurea. Em muitas ocasiões, a memória

51 Essa escola foi criada em 15 de novembro de 1908, durante o Governo de Alberto Maranhão. Suas atividades iniciaram em maio de $1909 \mathrm{com}$ Francisco Gurgel do Amaral, como seu diretor. Informação disponível em: http://ee30setembro100anos.blogspot.com/2010/04/um-breveresgate-historico-da-escola-30.html. Acesso em: 12 out. 2018.

52 A aprovação dessa lei gerou muitas discussões políticas e necessitou que Rio Branco e seus aliados articulassem, com ambos os partidos, os múltiplos interesses que a libertação dos recém-nascidos do ventre das escravas 
do Visconde do Rio Branco, tido no jornal como um dos responsáveis por impulsionador as ideias em torno do fim da escravidão, foi citada como o ponto de partida mais significativo à expansão da campanha abolicionista (COSTA, 2010, p. 54).

Nos discursos proferidos durante as comemorações, foi comum os representantes de O Mossoroense reforçarem esse posicionamento. Em 1910, Escóssia Filho leu um discurso para uma plateia de alunos e representantes das instituições públicas. O texto, de autor desconhecido, publicado no dia 09 de outubro, apontou a importância das comemorações e relacionou a trajetória jurídica da questão escravocrata ao 30 de setembro, a ponto de afirmar que a libertação dos escravos mossoroenses "representou um grande passo na jornada" que se iniciou em 28 de setembro de 1871 e foi concluída em 13 de maio de 1888.

Esse legado glorificante de nossos antepassados de hontem, que nós hoje aqui osculamos com o mais carinhoso desvanecimento e, a mais enthusiástica aclamação traduz para nós, representantes da nova geração um padrão de cívica nobreza, modelo primoroso das conquistas do futuro.

Eis, mocidade de Mossoró, vos que na frase do imortal cantôr dos escravos, sois o Moyses no Sinai, erguei a vossa fronte sobranceira ao morno bafejo da brisa de nossos verdes carnaubaes e de desta extendida sobre a arca santa de nossas brilhantes tradições, entoai o solemne compromisso de vossa atividade e másculas energias em prol da grandiosa tarefa da liberdade de nossa pátria, de que a emancipação dos captivos foi o prologo e a nossa verdadeira emancipação política será o complemento.

Assim cumprireis o vosso dever com o passado e realizareis as esperanças do futuro.

refletiam naquele momento tanto sobre o lugar que a Coroa ocuparia na questão da escravidão, quanto em relação ao controle do processo abolicionista que deveria ser feito sem causar revoltas dos escravos. Era necessária uma solução moderada para a tranquilidade pública e para a confiança dos proprietários diante das atribulações que a abolição poderia causar. 
Viva o dia 30 de setembro!

Viva Mossoró livre! (O MOSSOROENSE, p. 1, 1910).

O texto evidencia como a memória sobre o 30 de setembro transformou Mossoró em espaço de luta pela liberdade e tornou os Escóssias representantes desse discurso. Suas críticas repousaram sobre os vícios da política, retratados no clientelismo e no paternalismo, elementos característicos do regime republicano nas primeiras décadas, em termos de expansão dos direitos civis e políticos (CARVALHO, 1999, p. 45).

Diante desses posicionamentos, a busca pela legitimação do pioneirismo mossoroense no abolicionismo foi uma constante no exercício cotidiano do jornal dos Escóssias e nas instituições escolares, onde os discursos proferidos trouxeram à tona a memória sobre pessoas e lugares que, em seu conjunto, ficaram gravadas em poesias e outros documentos que listavam as ações dos que fizeram o 30 de setembro.

$\mathrm{Na}$ edição de 14 de maio de 1910, O Mossoroense apresentou o passado como herança e autointitulou-se como responsável pela sua manutenção na vida dos habitantes da cidade.

Como sempre, passou esta gloriosa data esquecida, entre nós, que, entretanto, representamos papel tão saliente no movimento abolicionista, tendo sido Mossoró o $2^{\circ}$ município livre em todo o vasto território do Brazil.

Nem ao menos as repartições públicas se lembraram de hastear seus pavilhões como sempre faz O Mossoroense que, por todos os meios, procura levantar bem alto a gloriosa tradição que nos legou a nossa história política, censurando sempre os que fugirem ao cumprimento deste dever quase sagrado. [...] O dia ' 13 de maio' que é o prolongamento do 30 de setembro, a data mais gloriosa da história de nossa civilisação, deveria ser sempre lembrada em nossa terra, e, o despontar deste sol, acariciado pelos beijos reconhecidos do povo mossoroense, ao som do immorredouro Hymno Libertador (O MOSSOROENSE, p. 1, 1910). 
Baseado na justificativa de que o 30 de setembro de 1883 foi o acontecimento local mais importante diante da história nacional, o jornal reivindicou um lugar para a libertação dos escravos no calendário cívico da cidade. Esse trabalho da família Escóssia torna evidente os interesses de associar a própria trajetória de Jeremias da Rocha Nogueira, patrono da família Escóssia, e de seu jornal, ao pioneirismo na luta que desembocou na campanha abolicionista.

O uso jornalístico do passado, feito por O Mossoroense, associou tanto a celebração do progresso, alardeada pela imprensa do início do século XX, quanto a crença de que o futuro promissor ainda encontraria, na exaltação do passado, o exemplo para sua realização (ELEUTÉRIO, 2008, p. 83-89).

Nessa perspectiva, a busca pela inserção da libertação dos escravos como data do calendário cívico da cidade seria, também, a incorporação da trajetória social e política da família Escóssia dentro do que foi considerado o mais importante momento da participação da cidade em nível nacional. Todo o empenho partiu do trabalho de jornalistas de uma cidade interiorana, eufóricos por uma exaltação que não encontrou nos principais centros do país ecos, e que se restringiu a ficar localizado e com pouca repercussão jornalística, daí o entendimento dos limites e significados do 30 de setembro para os Escóssias.

Esses limites e significados refletem o olhar que o próprio jornal possuía sobre o tempo social da cidade, uma vez que a relação entre passado e futuro continuavam a ser permeadas pelo exemplo que o passado teria na construção do futuro. Isso foi exposto em um contexto (início do século XX) em que as grandes cidades, como o Rio de Janeiro, passavam por consideráveis transformações, cuja percepção do tempo social, linear e orientado, tinha no "futuro, a redenção e, no passado, o esquecimento" (BARBOSA, 2007, p. 25).

A batalha pela memória expressa em O Mossoroense mostrou que, no início dos anos de 1920, a preocupação com os rumos das comemorações do 30 de setembro foi uma constante. Em meio ao enfraquecimento das comemorações, os Escóssias apelaram à população por uma maior participação nas festividades, tendo como justificativa a importância simbólica da data para a história local. 
Mossoró atravessa, positivamente, uma phase de decadência cívica, que urge remediar e remover, pela recordação systemathica e oportuna, em todos os centros e em todas as camadas populares, dos feitos patrióticos dos nossos antepassados. E nem de outra forma, nos mostraremos dignos, aos nossos próprios olhos, da herança que recolhemos e de que somos depositários e guardadores. A data anniversaria da abolição de todos os captivos residentes em território mossosoroense deveria ter sido outras manifestações de regosijo que não apenas a tradicional soirée dançante dos libertos e a festividade do "Democrata Club", a despeito de seu realce e imponência. As comemorações cívicas, para que alcancem a finalidade que se destinam, devem ter amplitude maior e repercussão mais extensa e mais larga (O MOSSOROENSE, p. 1, 1920).

Para os proprietários de O Mossoroense, ao chegarem aos clubes, as atividades comemorativas perdiam parte de sua publicidade e modificavam-se, tanto na ritualística como na essência necromântica de exaltação aos heróis do passado. No jornal, intensificou-se a retomada das comemorações com textos, como o do professor Joel de Carvalho, que enfatizou, a partir da narrativa do sofrimento dos negros escravos, a coragem e brilhantismo dos abolicionistas mossoroenses em desafiar a força dos proprietários de escravos.

Os gemidos de dôr e de angustia que ecoavam no fundo das senzalas, tocava-lhes o âmago do coração, incitando-os, cada vez mais, ao triunfo do seu benemérito desiderato.

A tribuna era liderada por Almino Afonso e a imprensa, por Jeremias da Rocha Nogueira, que ao lado de outros não menos entusiastas pela causa dominante, baniu os gládios da palavra, que eram como verdadeiras farpas flamejantes lançadas em praça pública, para devorar a dureza e a apatia dos adversários inconscientes da grande cruzada da maçonaria, a mater propulsora da liberdade dos povos, erguia também a sua espada de fogo a fulminar e partir os élos impiedosos (O MOSSOROENSE, p. 1, 1931). 
Observa-se que a fabricação da memória sobre o 30 de setembro pelos Escóssias trouxe, em seu arcabouço, a necessidade de inserir nomes que, até então, não eram citados como abolicionistas, como o de Jeremias da Rocha Nogueira, falecido em 26 de junho de 1881.

Patriarca da família Escóssia, fundador de O Mossoroense, militante do Partido Liberal, e maçom, a memória de Jeremias da Rocha Nogueira, como abolicionista, era indispensável ao sucesso da estratégia de incorporação do passado abolicionista à trajetória dos Escóssias. Mas, ao ser apresentado como abolicionista, logo surgiram questionamentos, como o do jornalista José Martins de Vasconcelos. No artigo "Adulterando a história sobre o 30 de setembro de 83 em Mossoró”, publicado no jornal Correio do Povo, o jornalista questionou a veracidade da inclusão de Jeremias Nogueira como abolicionista, alegando que ele não participara da campanha abolicionista (CORREIO DO POVO, p. 3, 1910).

Nesse aspecto, o processo de gestação da memória sobre Mossoró - cidade da liberdade - ganhou forma e sentido na evocação de um passado que teve como cerne os interesses de uma família que buscou um lugar na história da cidade. Entretanto, essa memória abolicionista não está restrita aos homens que lutaram pelo fim da escravidão, nela cabem também a idealização do "bom escravo", como foi narrado pelo professor Joel de Carvalho.

Rompem-se afinal as cortinas do firmamento azul, e no horizonte fulgidos da terra invicta de Rafael Mossoroense da Glória, surge a aurora radiosa para ouvir o epinício altissonante da grande vitória.

Era o 30 de setembro de 1883, que raiava grandioso e límpido como o sol brasileiro, ao ruído triunfal das grilhetas partidas.

Estavam libertos todos os escravos do nosso município, "Rafael, tú doravante és livre como o vento que sibila nos leques das nossas carnaubeiras!" - Disse o grande tribuno, ao dar áquelle a alcunha de Mossoroense da Glória.

Não sei se pode desejar feito mais sublime, episódio mais heroico, do que esse que nos legaram, num exemplo altiloquente de amor e de civismo aquele pugilo de espartanos tão nobres quão juntos, 
que hoje constituem a relíquia imperecível dos nossos dias e dos dias de amanhã.

Sejam, pois, benditos, muitas vezes benditos, hoje e sempre, esses "varões de Plutarco", que a 30 de setembro de 1883, escreveram com o gladio de seu feito de gigante, no bronze maciço da nossa História, essa tríplice legenda - Liberdade, Igualdade, Fraternidade (O MOSSOROENSE, p. 1, 27 set. 1931).

Símbolo das articulações que desembocaram no fim da escravidão e dos desdobramentos que suas ações passaram a ter com o famoso Clube dos Espartacos, similar ao Clube do Cupim, em Recife, Rafael Mossoroense da Glória é a idealização do ex-escravizado que agradece e honra a atitude das autoridades que o libertaram.

A referência ao Clube do Cupim no Recife é uma associação às atividades desenvolvidas pelo "Clube dos Espartacos em Mossoró - dar abrigo e amparo aos escravos" que chegavam a Mossoró. Na correspondência que os abolicionistas mossoroenses escreviam aos abolicionistas pernambucanos, a alusão ao transporte de libertos e as pressões pós-libertação local mostram como a libertação dos escravos em Mossoró manteve a tensão que a questão abolicionista propiciava e estava longe de ser resolvida por completo. Em carta enviada ao comerciante pernambucano João Ramos, em 28 de maio de 1884, Joaquim Bezerra da Costa Mendes (presidente da Sociedade Libertadora Mossoroense) expõe sua constante luta em prol da libertação nas áreas circunvizinhas e, por conta disso, afirma que continua "lutando com os infames e nojentos negreiros não só do interior como daqui! Ainda que nesta terra não tenha mais escravos!" (GALVÃO, 1982, p. 17).

Na correspondência, negócios e ideias estão juntos do comerciante abolicionista mossoroense. A luta para manter a empresa de compra de algodão e venda de produtos nacionais, mediante os obstáculos comerciais, advindos por partilhar posicionamentos sociais e políticos diante dos ideais abolicionistas, era uma constante (ROSADO, 1989, p. 36). A vida do comerciante pagou o ônus dos posicionamentos abolicionistas à medida que o esforço em encontrar parcerias na capital pernambucana era permeada pela necessidade de abertura de crédito 
para manter o fluxo comercial com o interior do oeste da Província do Rio Grande do Norte.

Joaquim Bezerra da Costa Mendes é exemplo dos atritos que marcaram a libertação dos escravos mossoroenses. Mesmo com um pequeno fluxo de escravos, Mossoró era o centro econômico irradiador do oeste, como tal, mantinha os vínculos socioeconômicos que a escravatura gerou, como foi o caso do comércio interprovincial que deslocou grande parte da mão de obra escrava das Província do Norte para São Paulo, Minas Gerais e Rio de Janeiro.

Com todo esse trânsito, Mossoró possuía particularidades viáveis à construção do processo libertário: era praça comercial; possuía poucos escravizados e suas autoridades políticas e jurídicas possuíam contato com as ideias abolicionistas, quer com sociedades libertadoras, como era o caso da ligação com a Sociedade Libertadora Cearense, quer com as ideias abolicionistas que circulavam entre as autoridades jurídicas locais, como o juiz Alcebíades Dracon. Com o apoio das principais autoridades locais e os interesses abolicionistas dos cearenses na Província do Rio Grande do Norte, a libertação dos escravos em Mossoró limitou-se às inclinações de sua elite em prol dos princípios do progresso que o trabalho livre representava naquele momento, ficando os ex-escravizados sem os meios necessários ao exercício da cidadania (CARVALHO, 2015, p. 57)

Assim, as narrativas jornalísticas sobre as comemorações da libertação dos escravos em Mossoró, especialmente no jornal O Mossoroense, evidenciam que, junto à lembrança do ato comemorativo, construíam-se os meios para esquecer resistências, tensões e limites à medida que se produzia, em nível local, uma memória gloriosa sobre o pioneirismo da cidade em uma das grandes questões das últimas décadas do Império, a abolição da escravidão. 


\section{REFERÊNCIAS}

13 DE MAIO. O Mossoroense, Mossoró, p. 1, 14 maio 1910.

15 DE NOVEMBRO. O Mossoroense, Mossoró, p. 1, 15 nov. 1904.

30 DE SETEMBRO. Correio de Natal, Natal, p. 1-4, 30 de set. 1883.

30 DE SETEMBRO. O Mossoroense, Mossoró, p. 3, 30 set. 1909.

30 DE SETEMBRO. O Mossoroense, Mossoró, p. 1, 9 out. 1910.

30 DE SETEMBRO. O Mossoroense, Mossoró, p. 1, 4 out. 1920.

A FALLA do Throno. O Mossoroense, Mossoró, p. 1, 11 jan. 1873.

A ESTÁTUA da Liberdade. O Mossoroense, Mossoró, p.

2, 30 set. 1904.

BARBOSA, M. História cultural da imprensa: Brasil - 19002000. Rio de Janeiro: Mauad X, 2007.

CARVALHO, J. M. Os Bestializados: o Rio de janeiro e a República que não foi. São Paulo: Companhia das Letras, 1987. 
CARVALHO, J. 30 de setembro. 0 Mossoroense, Mossoró, p. 1, 27 set. 1931.

CARVALHO, J. M. Pontos e bordados: escritos de história e política. Belo Horizonte: UFMG, 1999.

CARVALHO, J. M. Cidadania no Brasil: o longo caminho. 19. ed. Rio de Janeiro: Civilização Brasileira, 2015.

CATROGA, F. Nação, mito e rito: religião civil e comemoracionismo (EUA, França e Portugal). Fortaleza: Edições NUDOC; Museu do Ceará, 2005.

COSTA, E. V. A Abolição. 9. ed. São Paulo: UNESP, 2010.

DANTAS, J. H. A Imprensa em Mossoró. Mossoró: Fundação Vingt-Un Rosado, 2002.

DIEHL, A. A. Cultura historiográfica: memória, identidade e representação. Bauru, SP: EDUSC, 2002.

ELEUTÉRIO, M. L. Imprensa a serviço do progresso. In: MARTINS, A. L.; LUCA, T. R. (org.). História da imprensa no Brasil. São Paulo: Contexto, 2008.

FERNANDES, P. R. Mossoró: uma cidade impressa nas páginas de O Mossoroense (1872-1930). Dissertação (Mestrado em História) Universidade Federal de Campina Grande, Campina Grande, 2009.

GALVÃO, J. B. Subsídios para a história da abolição do cativeiro no Rio Grande do Norte. Mossoró: Fundação Vingt-un Rosado, 1982. (Coleção Mossoroense).

JOSÉ do Patrocínio. O Mossoroense, Mossoró, p. 1, 16 fev. 1905. 
KARNAL, L.; TATSCH, F. G. A memória evanescente. In: PINSKY, C. B.; LUCA, T. R. (org.). O historiador e suas fontes. São Paulo: Contexto, 2011.

LE GOFF, J. História e memória. Campinas: UNICAMP, 1996.

MACHADO, H. F. Imprensa e identidade do ex-escravo no contexto do pós-abolição. In: NEVES, L. M. B.; MOREL, M. P.; FERREIRA, T. M. B. C. (org.). História e imprensa: representações culturais e práticas de poder. Rio de Janeiro: DP\&A: Faperj, 2006.

PESAVENTO, S. J. Em busca de uma outra história: imaginando o imaginário. Revista Brasileira de História, São Paulo, v. 15, n. 29, 1995.

PROGRAMA. Libertador, Fortaleza, p. 1, 1 jan. 1881.

ROSADO, C. A. E. Escóssia. Mossoró: Fundação Vingt-un Rosado, 1998. (Coleção Mossoroense. Série C, v. 989).

ROSADO, C. A. E. Síntese histórica de O Mossoroense. Mossoró, RN: Fundação Guimarães Duque, 1992.

ROSADO, J. V. Repercussões pernambucanas do movimento abolicionista mossoroense. Mossoró: Fundação Vingt-un Rosado, 1989. (Coleção Mossoroense. Série B, v. 507).

VASCONCELOS, J. M. Adulterando a história sobre o 30 de setembro de 1883 em Mossoró. Correio do Povo, Mossoró, p. 3, 4 out. 1910 . 